\title{
Regional Flooding Induced by Tide and Warm Water Effects in Tuvalu
}

\author{
Chen-Chih Lin, Chung-Ru Ho*, Yu-Hsin Cheng, and Shin-Jye Liang \\ Department of Marine Environmental Informatics, National Taiwan Ocean University, Keelung, Taiwan, R.O.C.
}

Received 30 December 2013, accepted 2 December 2014

\begin{abstract}
A statistical model for simulating flood inundation in Tuvalu is developed in this study. The model is based on the major regional inundation factors - spring tides and warm-water mass, integrated with the digital elevation. Nineteen years of sea level data from tide gauge and satellite altimetry are analyzed to predict regional flooding. Harmonic analysis is used in analyzing tidal variations to determine the major astronomical tidal constituent harmonic constants. Tidal variation prediction can be performed with these harmonic constants. The empirical mode decomposition (EMD) method is then applied to the sea level data derived from altimetry for extracting warm-water mass variation. Ninety percent of sea level data points are used for analysis, and the remaining $10 \%$ are used for testing the prediction accuracy. The sea level data derived from along-track satellite altimeter near Tuvalu is decomposed into eight modes and one local trend using the EMD method. The EMD mode periods found by fast Fourier transform (FFT) include monthly, intra-seasonally, half-yearly, yearly, bi-annually, and interannually oscillations. We apply these periods to harmonic analysis to predict the variations in warm-water mass. The sea level tide and warm-water mass combination predictions are compared to field measurements. The results show that the correlation coefficient is 0.988 with a root-mean-square error (RMSE) of $7.6 \mathrm{~cm}$.
\end{abstract}

Key words: Flooding, Sea-level rise, Tuvalu, Warm water

Citation: Lin, C. C., C. R. Ho, Y. H. Cheng, and S. J. Liang, 2015: Regional flooding induced by tide and warm water effects in Tuvalu. Terr. Atmos. Ocean. Sci., 26, 213-218, doi: 10.3319/TAO.2014.12.02.06(EOSI)

\section{INTRODUCTION}

As sea-levels continue to rise due to global warming and climate change, human habitats are becoming increasingly threatened. Sea level is projected to increase between $0.09-0.88 \mathrm{~m}$ by the year 2100 (Church et al. 2001). The $5^{\text {th }}$ IPCC Report predicted a sea level rise of $0.26-0.82 \mathrm{~m}$ by the end of the century. With a proportionality constant prediction of $3.4 \mathrm{~mm}$ year $^{-1}{ }^{\circ} \mathrm{C}^{-1}$ by Rahmstorf (2007), the projected sea-level rise in 2100 will be $0.5-1.4 \mathrm{~m}$ above the 1990 level. Although model simulations that estimate sea level rise have been significantly debated, the fact that coastal cities and island countries in the tropical oceans are challenged by the dramatic impact of rising sea levels (Pyper 2007). As with many hazards caused by rising sea levels, inundation and flooding has become common threats to people.

Tuvalu, as shown in Fig. 1, is a low-lying island country with its highest elevation less than $5 \mathrm{~m}$. It is broadly considered to be one of the island countries most threatened

\footnotetext{
* Corresponding author

E-mail:b0211@mail.ntou.edu.tw
}

by sea level rise (Church et al. 2006; Webb 2006; Mimura et al. 2007; Wong 2011). Due to the elevation and the vulnerable characteristics of reef islands, any oceanic influential factors, such as tropical cycles, surges or erosion are made worse by human activity (Eschenbach 2004; Yamano et al. 2007; Webb and Kench 2010; Lin et al. 2014). The composition and elevation of atoll islands display the disadvantages of inhabiting such islands. The central part of the island was formerly dominated by swamp land that floods easily at high tides (Yamano et al. 2007). The reef is inundated with small holes in the porous atoll ground that allows sea water to seep through. This sea water kills crops and contaminates freshwater, reducing agricultural productivity (Mortreux and Barnett 2009). Other vulnerability factors include anthropogenic effects on carry capacity, economic development and war costs (McQuarrie 1994). The causes and effects of regional flooding in Tuvalu has been identified and discussed in Lin et al. (2014) which illustrated the flooding was strengthened mainly by spring tide and warm-water mass. The warm water is an eddy-like water 
mass which is generated by instability waves from eastern tropical Pacific Ocean (Fig. 2).

This study develops a flooding prediction model applied to reef islands by integrating the spring tide signals and warm water effects. Digital elevation data is used to evaluate the flooding effect on the island. A warning signal is presented when the sea level accumulates with the ascending spring tide and the associated thermal expansion of warm water. Once the sea level exceeds the alarm sea surface height, flooding warning prediction is considered.

\section{DATA}

Hourly tide gauge data for the period of record 1993 2012 were obtained from an updated version of the qualitycontrolled South Pacific Sea Level and Climate Monitoring Project (SPSLCMP), sponsored by the Australian Agency for International Development (AusAID). The Sea Level Fine
Resolution Acoustic Measuring Equipment (SEAFRAME) gauge in Tuvalu was installed in 1993, offering accurate sea level measurement data with the assistance of Continuous Global Positioning System (CGPS) network and Tide Gauge Bench Mark (TGBM) for vertical movement.

Sea surface height anomaly (SSHA) data are accessed from Archiving Validation and Interpretation of Satellite Data in Oceanography (AVISO) through March 1993 to November 2012. The along track sea level data is a merged product derived from TOPEX/Poseidon, Jason-1, and Jason-2 satellite altimetry with $6-\mathrm{km}$ spatial resolution and 10-day temporal intervals. The data were interpolated to one datum each hour to match with the tide gauge data.

Elevation is one of the interrelated factors that determine land vulnerability to the effects of flooding. Some of the inland elevation in this study case is lower than the coast. The physical characteristics of coral islands and the permeable stratum of coral reef make the flooding detection more

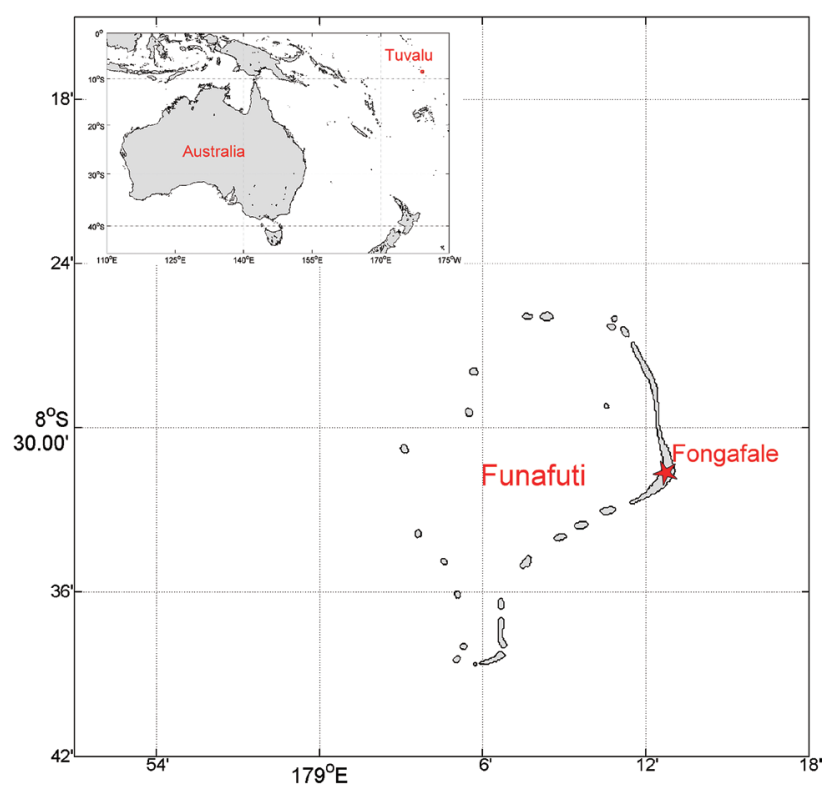

Fig. 1. The position of Fongafale, Tuvalu. The upper left map is the relative position of Tuvalu and Australia.

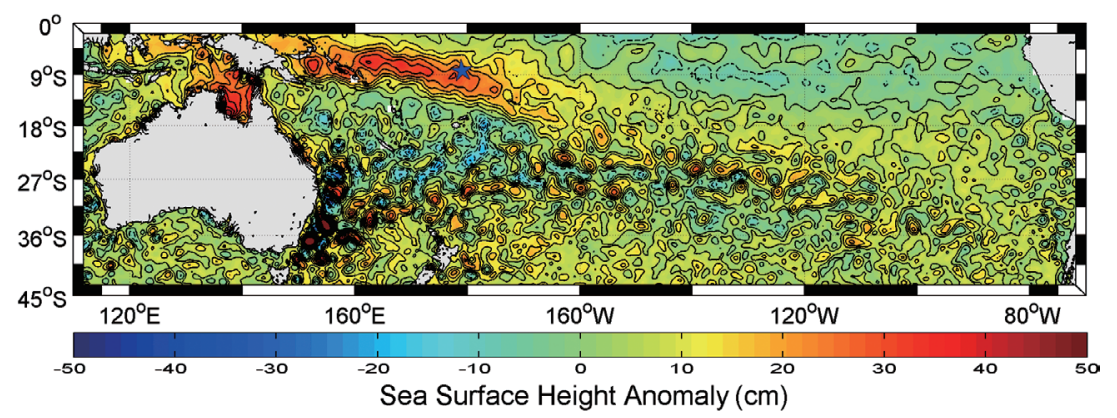

Fig. 2. An example of sea surface height anomaly (SSHA) during a King Tide event (28 February 2006). The blue star indicates the position of Tuvalu. Color bar shows the SSHA by centimeter. Red color presents the warm-water mass; while blue presents the cold-water mass. This image is a 7-day average datum. 
obscure. We require accurate spatial analyses of horizontal and vertical resolutions on the extent and timing of flooding to evaluate the coral island vulnerability. The digital elevation (Fig. 3) is based on Yamano et al. (2007) from a static GPS survey with sub-centimeter positional accuracy in two dimensions.

\section{METHODOLOGY}

A statistical flooding prediction model relies on past data accessed from tide gauge and satellite altimeter. The original tidal data accessed from the tide gauge was calculated using harmonic analysis to decompose the tidal constitutes. The empirical mode decomposition (EMD) method decomposes the sea level signals from the satellite altimeter into a few main modes. The fast Fourier transform (FFT) is computed to convert time into frequency based on the satellite altimeter data.

\subsection{Harmonic Analysis}

We processed the 19-year tide gauge and satellite altimeter data mapped on the digital topography in Fongafale and simulated the possible flooding time and area. In a typical oceanic time series tidal variability is often the largest signal. The harmonic method is one of the most popular ways to analyze tidal characteristics and an approach to calculate the amplitudes and phases of tidal constituents. The tidal signal, modeled as the sum of a finite set of sinusoids at specific frequencies, is related to astronomical parameters. These frequencies are specified by various combinations of sums and differences from six fundamental frequencies arising from planetary motions (Godin 1972). The tidal level $Y(t)$ can be described by the linear cosine and sine functions as

$Y(t)=a_{0}+\sum_{i=1}^{M}\left(a_{i} \cos \omega_{i} t+b_{i} \sin \omega_{i} t\right)$

where $a_{0}$ is the mean sea level, $a_{i}, b_{i}(i=1,2, \ldots, M)$ indicates the amplitude of the $i^{\text {th }}$ constituent; $\omega_{i}$ is the frequency of the $i^{\text {th }}$ constituent; and $t$ means time.

Ninety percent of the 19-year tide gauge data span accessed from SPSLCMP were taken as the basic data for testing the flooding model. The remaining $10 \%$ data is used for comparison. The barometric pressure influence was filtered before harmonic analysis. Tidal composition was performed to extract the amplitudes of 69 constituent frequencies.

The sea surface height at an arbitrary point $\eta(t)$ can be transformed into a simplified expression as (Yan et al. 1994):

$\eta(t)=m+\sum_{j=1}^{l}\left(a_{j} \cos \omega_{j} t+b_{j} \sin \omega_{j} t\right)$

where $m$ is the mean sea level, $a_{j}$ and $b_{j}(j=1, \ldots, l)$ indicates the amplitude of the $j^{\text {th }}$ component, $\omega_{j}$ is the angular frequency of the $j^{\text {th }}$ component, and $t$ is the time. This equation is exactly the same as Eq. (1). Therefore, the harmonic constant of each sea surface height frequency can be extracted and the sea surface height can be further predicted using these harmonic constants and frequencies.

\subsection{EMD}

The EMD method (Huang et al. 1998) is adapted to determine the sea surface height frequency data around Tuvalu. EMD is an empirical method that can decompose a time series signal into a few intrinsic mode functions (IMFs). After removing the IMF numbers from the original time series signal, the remaining data show the local trend. The structure of each IMF is determined by the natural amplitude variations in the time series. For a given time series signal $x(t)$, with time $t$, EMD ends up with a representation of the form:

$x(t)=\sum_{i=1}^{n} d_{i}(t)+r_{n}(t)$

where $r_{n}(t)$ is the local trend and the $d_{i}(t)(i=1, \ldots, n)$ are constrained to be zero-mean amplitude modulation frequency. As such, EMD proves especially efficient in those deterministic
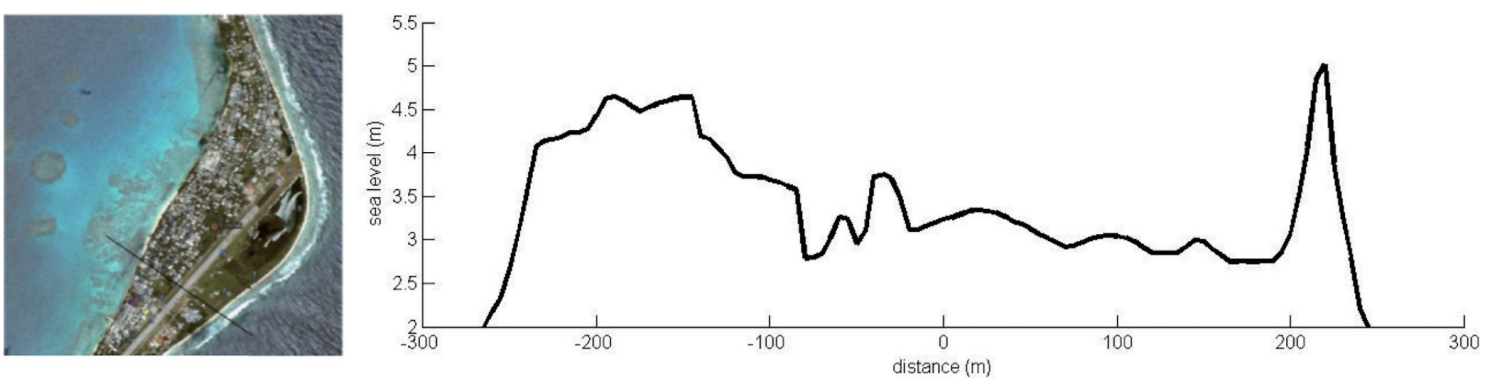

Fig. 3. The terrain profile of Fongafale, Tuvalu. Right map is drawn in black line profile in the left image. The framework (right) is form Yamano et al. (2007); while the image of Fongafale (left) is from Google Map. 
situations which precisely enter the framework of sinusoidal models (Flandrin et al. 2004). We perform the EMD method on the sea surface height data near Tuvalu from 24 March 1993 to 24 November 2010 (90\% of the whole data). Eight IMFs and one local trend are found and are shown in Fig. 4.

\subsection{FFT}

The approximate frequency of each IMF can be identified by FFT. FFT is a mathematical method for transforming a function of time into a function of frequency. It is very useful for time-dependent phenomena analysis and widely used for many applications in engineering, science and mathematics. In the sea surface height decomposition process the periods found by FFT analysis from EMD modes are eight periods including monthly, two intra-seasonal, half-yearly, annual, bi-annual, and two inter-annual oscillations, respectively. We employ these periods to the harmonic analysis for prediction.

\section{FLOODING ESTIMATION}

The harmonic tide reconstruction data were combined with warm water, and the result was compared with the remaining $10 \%$ original data. Figure 5 shows a comparison of both time series datasets and their scatter plots. The correlation coefficient of both data is 0.988 with a root-meansquare error (RMSE) of $7.6 \mathrm{~cm}$, which is about one twentieth of the signal. This error is acceptable for prediction of flooding from the observation data using harmonic analysis methodology.

To simulate the sea-level fluctuation in the capital of Tuvalu, Fongafale, we digitized the Fongafale topogra- phy based on the elevation data of Yamano et al. (2007) as shown in Fig. 3. Fongafale is a coral reef island in which water can permeate easily through the porous underground. Once the sea level rises higher than the average elevation of Fongafale, about half of the Fongafale area is under the threat of flooding. Figure 6 depicts the inundation area during the average spring tide of $2.7 \mathrm{~m}$ and King Tide period of sea level $3.2 \mathrm{~m}$. King Tide was defined and discussed by Lin et al. (2014) as the average island elevation. King Tide occurs once or twice a year on average. The terrain profile illustrates that spring tide will not cause damage to local people, but King Tide severely threatens Tuvaluans life and property.

\section{CONCLUSION}

The scientific understanding determines the various causes and dynamic processes involved in flooding, especially in extreme events (Hunt 2005). Advances in data analysis also make remote sensing systems practical and attractive for monitoring natural and man-induced sea-level changes (Klemas 2011). This study developed and applied a statistical prediction flooding model. Tuvalu flooding is caused mainly by the spring tide and warm-water mass. Other factors include climatic activity and anthropogenic effects (Lin et al. 2014). For some areas, simple inundation will be the primary response to sea-level rise. Human life is the most critical factor in assessing potential impacts. An appropriate estimation can mitigate the damage to life and property and give people understanding to the hazards caused by humans and nature. With the proposed flooding model we can predict flooding scenarios and identify the potential inundation areas in low-lying reef islands.

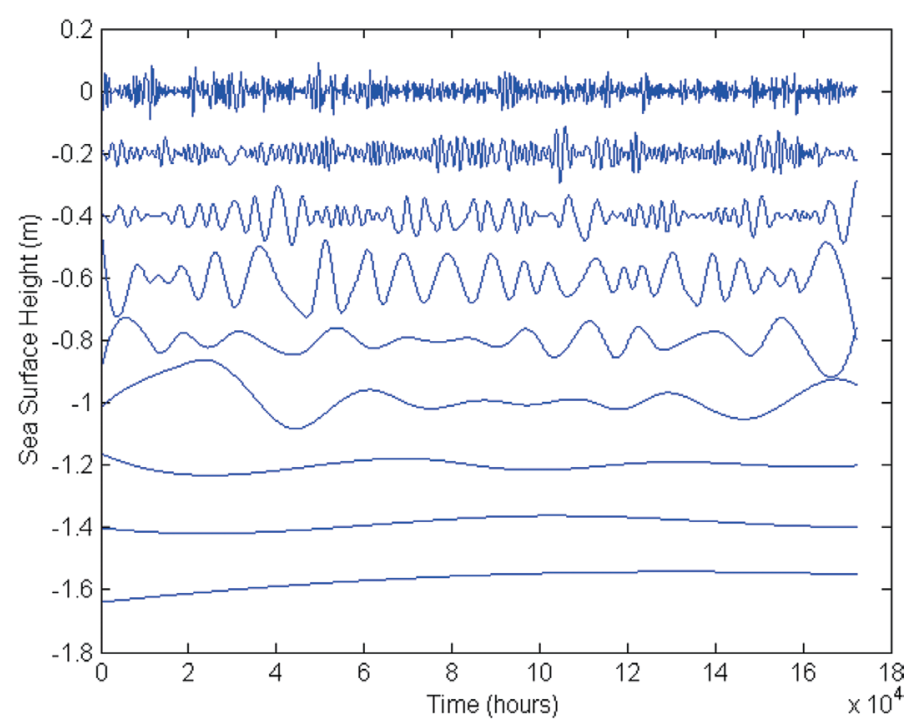

Fig. 4. The intrinsic mode functions (IMFs) and local trend of sea surface height decomposed by EMD (empirical mode decomposition). Each plot is shifted by $-0.2 \mathrm{~m}$. The last plot is the local trend. 
(a)

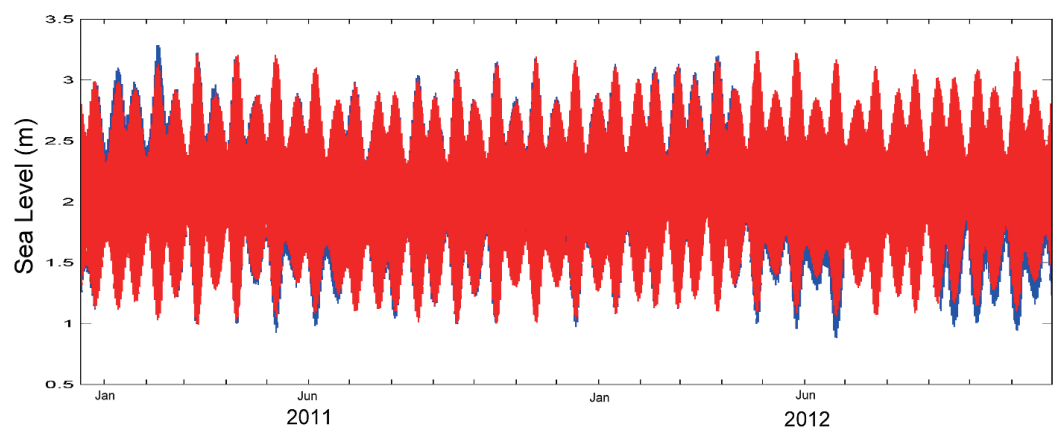

(b)

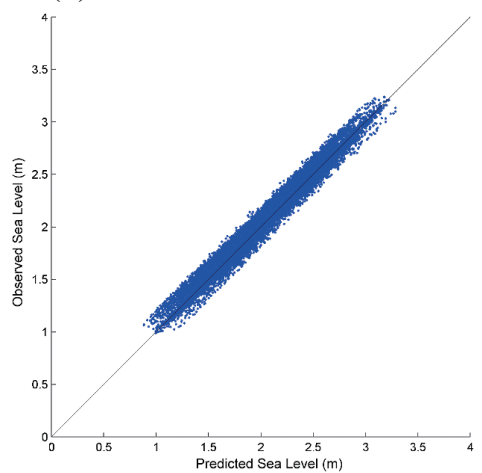

Fig. 5. (a) Time series of observation data (blue) and prediction data (red). (b) Scatter plot of both data.
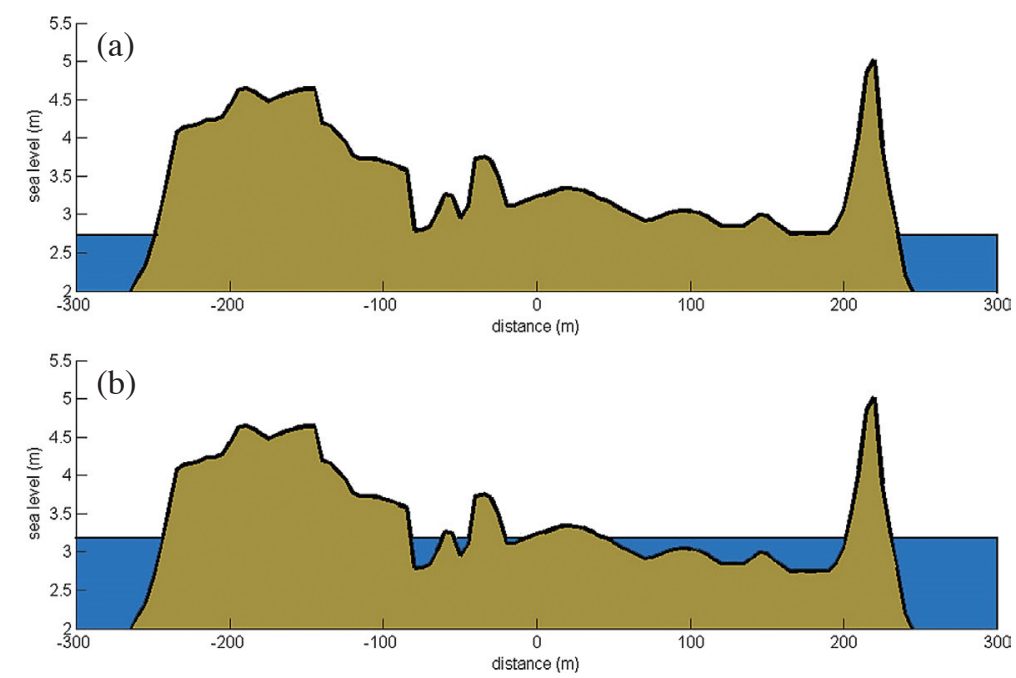

Fig. 6. The terrain profile and inundation area in (a) the sea level image in average spring tide of $2.7 \mathrm{~m}$, and (b) King Tide duration with the sea level of $3.2 \mathrm{~m}$.

Acknowledgements The tide gage and satellite altimeter data were accessed from SPSLCMP and AVISO, respectively. This work was partly supported by the Ministry of Science and Techonology of Taiwan through grant NSC1022611-M-019-011.

\section{REFERENCES}

Church, J. A., J. M. Gregory, P. Huybrechts, M. Kuhn, K. Lambeck, M. T. Nhuan, D. Qin, and P. L. Woodworth, 2001: Changes in sea level. In: Houghton, J. T., Y. Ding, D. J. Griggs, M. Noguer, P. J. van der Linden, X. Dai, K. Maskell, and C. A. Johnson (Eds.), Climate Change 2001: The Scientific Basis, Contribution of Working Group I to the Third Assessment Report of the Intergovernmental Panel on Climate Change, Cambridge University Press, Cambridge, U.K., 639-693.

Church, J. A., N. J. White, and J. R. Hunter, 2006: Sealevel rise at tropical Pacific and Indian Ocean islands.
Global Planet. Change, 53, 155-168, doi: 10.1016/j. gloplacha.2006.04.001. [Link]

Eschenbach, W., 2004: Tuvalu not experiencing increased sea level rise. Energ. Environ., 15, 527-543, doi: 10.1260/0958305041494701. [Link]

Flandrin, P., G. Rilling, and P. Goncalvés, 2004: Empirical mode decomposition as a filter bank. IEEE Signal Proc. Let., 11, 112-114, doi: 10.1109/LSP.2003.821662. [Link]

Godin, G., 1972: The Analysis of Tides, University of Toronto Press, $264 \mathrm{pp}$.

Huang, N. E., Z. Shen, S. R. Long, M. C. Wu, H. H. Shih, Q. Zheng, N. C. Yen, C. C. Tung, and H. H. Liu, 1998: The empirical mode decomposition and the Hilbert spectrum for nonlinear and non-stationary time series analysis. P. Roy. Soc. A-Math. Phy., 454, 903-995, doi: 10.1098/rspa.1998.0193. [Link]

Hunt, J. C. R., 2005: Inland and coastal flooding: Developments in prediction and prevention. Phil. Trans. 
Roy. Soc. Lond., 363, 1475-1491, doi: 10.1098/ rsta.2005.1580. [Link]

Klemas, V., 2011: Remote sensing of wetlands: Case studies comparing practical techniques. J. Coast. Res., 27, 418427, doi: 10.2112/JCOASTRES-D-10-00174.1. [Link]

Lin, C. C., C. R. Ho, and Y. H. Cheng, 2014: Interpreting and analyzing King Tide in Tuvalu. Nat. Hazards Earth Syst. Sci., 14, 209-217, doi: 10.5194/nhess-14209-2014. [Link]

McQuarrie, P., 1994: Strategic Atolls: Tuvalu and the Second World War, Macmillan Brown Centre, University of Canterbury, Christchurch, 187 pp.

Mimura, N., L. Nurse, R. McLean, J. Agard, L. Briguglio, P. Lefale, R. Payet, and G. Sem, 2007: Small islands. In: Parry, M. L., O. F. Canziani, J. P. Palutikof, P. J. van der Linden, and C. E. Hanson (Eds.), Climate Change 2007: Impacts, Adaptation and Vulnerability, Contribution of Working Group II to the Fourth Assessment Report of the Intergovernmental Panel on Climate Change, Cambridge University Press, Cambridge, U.K., 687-716.

Mortreux, C. and J. Barnett, 2009: Climate change, migration and adaptation in Funafuti, Tuvalu. Global Environ. Chang., 19, 105-112, doi: 10.1016/j. gloenvcha.2008.09.006. [Link]

Pyper, W., 2007: Preparing for sea-level rise. ECOS, 137,
14-17.

Rahmstorf, S., 2007: A semi-empirical approach to projecting future sea-level rise. Science, 315, 368-370, doi: 10.1126/science.1135456. [Link]

Webb, A., 2006: Tuvalu Technical Report - Coastal Change Analysis Using Multi-Temporal Image Comparisons Funafuti Atoll, EU EDF 8/9, SOPAC Project Report 54, Reducing Vulnerability of Pacific ACP States.

Webb, A. P. and P. S. Kench, 2010: The dynamic response of reef islands to sea-level rise: Evidence from multidecadal analysis of island change in the Central Pacific. Global Planet. Change, 72, 234-246, doi: 10.1016/j. gloplacha.2010.05.003. [Link]

Wong, P. P., 2011: Small island developing states. WIREs Clim. Change, 2, 1-6, doi: 10.1002/wcc.84. [Link]

Yamano, H., H. Kayanne, T. Yamaguchi, Y. Kuwahara, H. Yokoki, H. Shimazaki, and M. Chikamori, 2007: Atoll island vulnerability to flooding and inundation revealed by historical reconstruction: Fongafale Islet, Funafuti Atoll, Tuvalu. Global Planet. Change, 57, 407-416, doi: 10.1016/j.gloplacha.2007.02.007. [Link]

Yan, X. H., Q. Zheng, C. R. Ho, C. K. Tai, and R. E. Cheney, 1994: Development of the pattern recognition and the spatial integration filtering methods for analyzing satellite altimeter data. Remote Sens. Environ., 48, 147158, doi: 10.1016/0034-4257(94)90137-6. [Link] 